\title{
Characteristics of atmospheric density spectra in the mesopause region at Wuhan, China during March 1996
}

\author{
Yong $\mathrm{Ai}^{1}$, Xunjie Zhang ${ }^{2}, \mathrm{Su} \mathrm{Lu}^{1}$, and Shunsen Gong ${ }^{2}$ \\ ${ }^{1}$ Department of Radio Physics, Wuhan University, Wuhan 430072, China \\ ${ }^{2}$ Wuhan Institute of Physics and Mathematics, The Chinese Academy of Science, Wuhan 430071, China
}

(Received September 13, 1997; Revised February 2, 1998; Accepted February 20, 1998)

\begin{abstract}
Sodium layers (75-105 km) were measured by Na lidar on three nights from 1 to 3 of March 1996. The lidar data were used to calculate the Na density profiles and the atmospheric density spectra. The vertical wave number spectra exhibit power-law shapes with average slopes of -2.38 and magnitude at $m=2 \pi /(3 \mathrm{~km})$ of $8.40 \times 10^{5}\left(\mathrm{~m}^{2} \mathrm{~s}^{-}\right.$ $\left.{ }^{2}\right) /(\mathrm{cyc} / \mathrm{m})$ in the mesopause region.
\end{abstract}

\section{Introduction}

Gravity waves have a significant influence on the wind, temperature and density structure of the middle and upper atmosphere. During the past decade wave activity has been studied extensively, using both radar and lidar techniques (Beatty et al., 1992; Senft et al., 1993; Manson et al., 1997). These observations have provided important information on wave amplitudes, periods and wavelengths and on the statistical characteristics of the wave spectra. In February 1996, Wuhan Institute of Physics and Mathematics installed a Na lidar at Wuhan observatory $\left(30^{\circ} 32^{\prime} \mathrm{N}, 144^{\circ} 22^{\prime} \mathrm{E}\right)$. The system was operated as a Rayleigh and $\mathrm{Na}$ lidar for 3 days from 1 to 3 March 1996. The description of Na lidar system and the measurements of the shapes of sodium layers in the mesopause regions have been summarized by Gong et al. (1997) and Ai et al. (1998). In this paper we present our measurements of gravity wave atmospheric density spectra in the mesopause regions.

\section{Lidar System and Experimental Data}

Figure 1 is a block diagram of the Na lidar system. The pulsed laser is tuned to the $\mathrm{D}_{2}$ resonant absorption line of $\mathrm{Na}$ at a wavelength near $589 \mathrm{~nm}$ which is in the yellow-orange region of the visible spectrum. Kiton red dye was used in the dye laser. Laser pulse energy is about $50 \mathrm{~mJ}$, pulse width is about $10 \mathrm{~ns}$, photon counter operated with a $1.28 \mu$ s receiver range-gate which corresponds to a range bin length of 192 $\mathrm{m}$. The Na lidar system was operated during the nights of $1-$ 3 March 1996. The experiments lasted 144 minutes each night. The lidar observed at zenith and the raw data consist of photon count profiles obtained by accumulating the returns from 4800 laser pulses collected over a period of 4 min. A typical photon count profile is plotted in Fig. 2. The resonant scattering from the Na layer between about 80 and $105 \mathrm{~km}$ is clearly evident. The nonzero count level is caused

Copy right (C) The Society of Geomagnetism and Earth, Planetary and Space Sciences (SGEPSS); The Seismological Society of Japan; The Volcanological Society of Japan; The Geodetic Society of Japan; The Japanese Society for Planetary Sciences. primarily by background noise from scattered moonlight and starlight. The high photon count levels below $60 \mathrm{~km}$ result from Rayleigh (i.e. molecular) and Mie scattering by air molecules and aerosols. There were no clouds during any of the observations. From the raw data and by using reference temperature and pressure data from a March 1986 middle atmosphere model $\left(30^{\circ} \mathrm{N}\right)$, we calculated absolute $\mathrm{Na}$ density profiles from which it is possible to deduce the relative atmospheric density perturbations.

\section{Atmospheric Density Spectra}

Because the atmospheric transmittance depends on the clarity of the lower atmosphere and is not easy to measure, the absolute $\mathrm{Na}$ density is usually compute by normalizing the $\mathrm{Na}$ photocounts by the Rayleigh photocounts at an altitude free of aerosols, typically $30-35 \mathrm{~km}$. The absolute $\mathrm{Na}$ density can be written as (Liu, 1989)

$$
\rho_{s}(z)=\frac{z^{2} \sigma_{\mathrm{R}} \rho_{a}\left(z_{\mathrm{R}}\right)}{z_{\mathrm{R}}^{2} \sigma_{\text {eff }}} \frac{\left[N_{s}(z)-N_{\mathrm{B}} R_{\mathrm{L}} \Delta t\right]}{\left[N_{\mathrm{R}}\left(z_{\mathrm{R}}\right)-N_{\mathrm{B}} R_{\mathrm{L}} \Delta t\right]}
$$

where $N_{s}(z)=$ expected number of $\mathrm{Na}$ and background photons detected in the range interval $(z-\Delta z / 2, z+\Delta z / 2)$; $N_{\mathrm{R}}\left(z_{\mathrm{R}}\right)=$ expected number of Rayleigh scattering and background photons detected in the range interval $\left(z_{\mathrm{R}}-\Delta z /\right.$ $\left.2, z_{\mathrm{R}}+\Delta z / 2\right) ; \rho_{s}(z)=\mathrm{Na}$ density at range $z\left(\mathrm{~m}^{-3}\right) ; \rho_{a}\left(z_{\mathrm{R}}\right)=$ atmospheric density at the normalizing altitude $z_{\mathrm{R}}\left(\mathrm{m}^{-3}\right) ; N_{\mathrm{B}}$ $=$ expected photocount per range bin per pulse due to background noise and dark counts; $\sigma_{\text {eff }}=$ effective $\mathrm{Na}$ backscatter cross section $\left(\mathrm{m}^{2}\right) ; \sigma_{\mathrm{R}}=$ Rayleigh backscatter cross section $\left(\mathrm{m}^{2}\right) ; R_{\mathrm{L}}=$ laser pulse rate $\left(\mathrm{s}^{-1}\right) ; \Delta t=$ integration time (s).

According to Eq. (1), from the raw data we can get the absolute $\mathrm{Na}$ density distributions, and we also can get $\mathrm{Na}$ density perturbations $r_{s}(z, t)$

$$
r_{s}(z, t)=\frac{\rho_{s}{ }^{\prime}(z)}{\rho_{0}(z)}=\frac{\rho_{s}(z)-\rho_{0}(z)}{\rho_{0}(z)}
$$




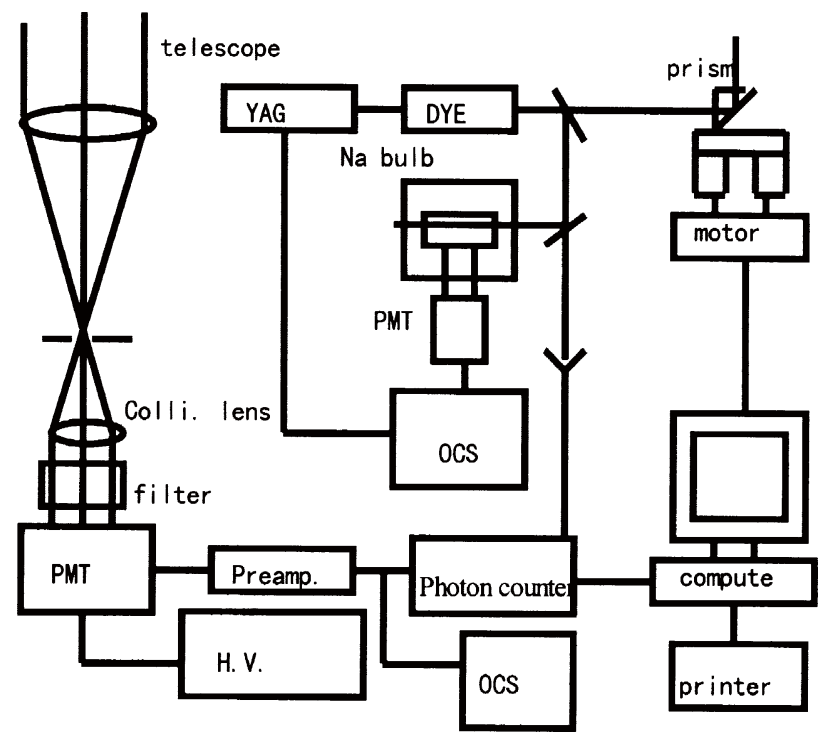

Fig. 1. Block diagram of Na resonance fluorescene lidar system.

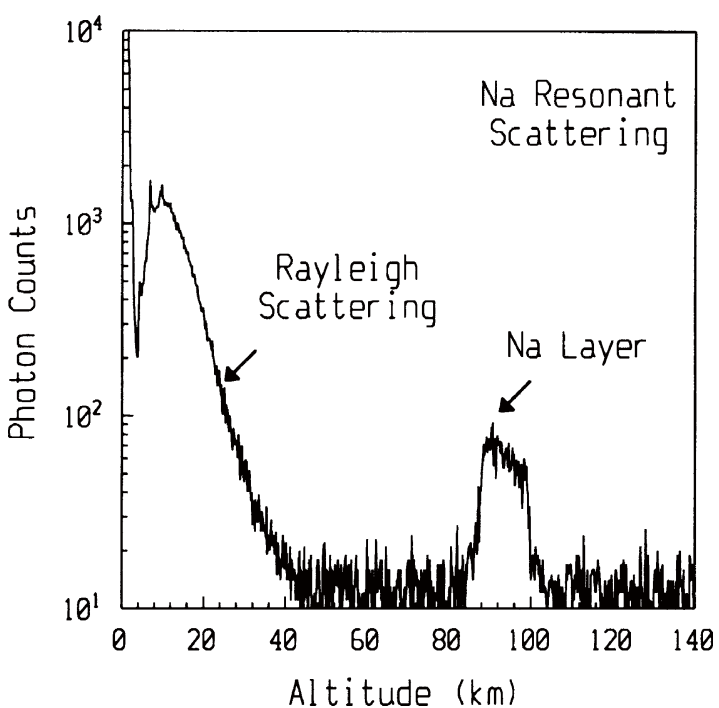

Fig. 2. Lidar photon count profile observed at 21:08 LST of 2 March 1996.

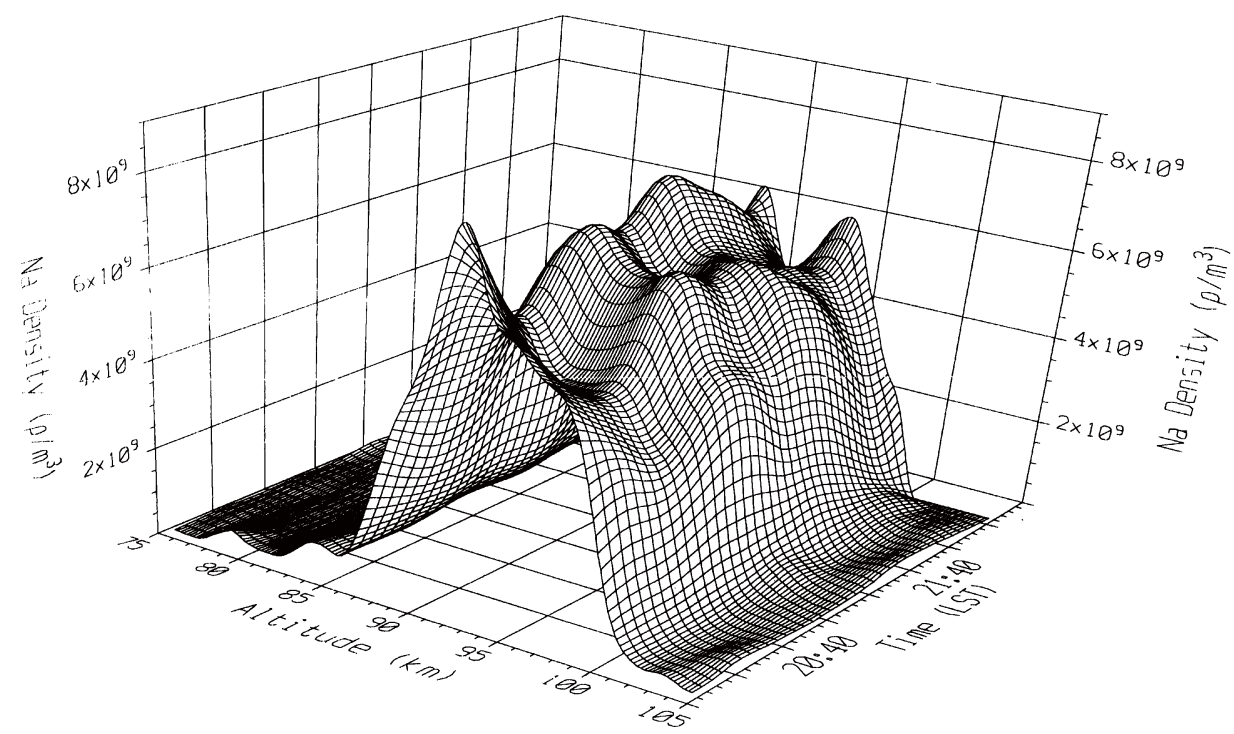

Fig. 3. The distribution of Na density with altitude and the changing relation of the profiles with time that observed on 2 March 1996 . The profiles have been plotted on a linear scale at 4 minutes intervals.

where $\rho_{0}(z)$ is unperturbed Na profile. The prime denotes the perturbation quantity.

It has been shown that a reasonably accurate model for the unperturbed $\mathrm{Na}$ layer is a Gaussian profile (Gardner and Voelz, 1987)

$$
\rho_{0}(z)=\frac{C_{0}}{\sigma_{0} \sqrt{2 \pi}} \exp \left[-\frac{\left(z-z_{0}\right)^{2}}{2 \sigma_{0}^{2}}\right]
$$

where $C_{0}=$ Na column abundance $\left(\sim 5 \times 10^{9} \mathrm{~cm}^{-2}\right) ; z_{0}=$ layer centroid height $(\sim 92 \mathrm{~km}) ; \sigma_{0}=$ r.m.s. layer width $(\sim 4.3 \mathrm{~km})$.

The distribution of $\mathrm{Na}$ density with altitude and the changing relation of the profiles with time is shown in Fig.
3. The profiles have been plotted on a linear scale at $4 \mathrm{~min}$ intervals. The wavelike structure in the profiles is caused by the wind perturbations associated with low-frequency internal gravity wave. If the vertical extent of the Na layer is large compared to the vertical correlation length of the density or wind perturbations, then the vertical wavenumber spectra of the $\mathrm{Na} F_{s}\left(k_{z}\right)$ and atmospheric density fluctuations $F_{a}\left(k_{z}\right)$ are related (Liu, 1989)

$$
F_{S}\left(k_{z}\right)=\frac{\left\langle\left|R_{S}\left(k_{z}, t\right)\right|^{2}\right\rangle}{L} \approx \frac{1}{\mu^{2}} F_{a}\left(k_{z}\right)
$$



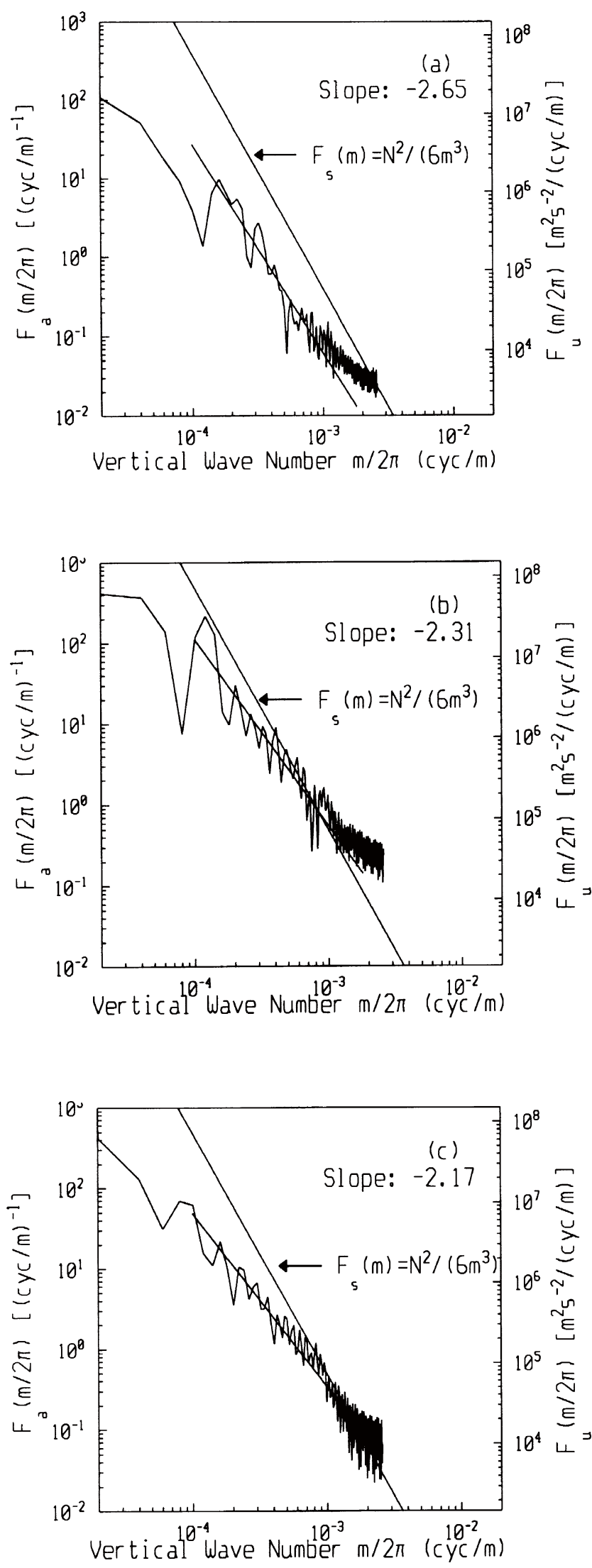

Fig. 4. Vertical wavenumber power spectra of the atmospheric density perturbation associated with internal gravity waves in the mesopause region. The spectra were inferred from $\mathrm{Na}$ lidar data collected at Wuhan on 1 (a), 2 (b), and 3 (c) March 1996. The straight lines are linear regression fits to the spectra for 1 to $10 \mathrm{~km}$ wavelength. The saturated power spectral density model is also plotted in the figure.

$$
\mu^{2}=\frac{(\gamma-1)^{2}}{\left[1+\left(\gamma H L / \sigma_{0}^{2}\right)^{2} / 12\right]}
$$

and $R_{s}\left(k_{z}, t\right)$ is the Fourier transforms of $r_{s}(z, t)$

$$
R_{S}\left(k_{z}, t\right)=\int_{z_{0}-L / 2}^{z_{0}+L / 2} r_{s}(z, t) e^{i k_{z} z} d z
$$

In Eq. (5), $\sigma_{0}=$ r.m.s. thickness of the unperturbed $\mathrm{Na}$ layer $(\sim 4.3 \mathrm{~km}), z_{0}=$ centroid height of the unperturbed $\mathrm{Na}$ layer $(\sim 92 \mathrm{~km}), H=$ atmospheric scale height $(\sim 6 \mathrm{~km}), \gamma=$ ratio of specific heats (1.4).

Although Rayleigh and $\mathrm{Na}$ lidar measure density, the gravity wave polarization and dispersion relation can be used to relate the mean-square atmospheric density perturbations and density power spectra $F_{a}\left(k_{z}\right)$ to the mean-square horizontal wind perturbations $\left\langle u^{2}\right\rangle$ and horizontal wind power spectra $F_{u}\left(k_{z}\right)$ (Liu, 1989).

$$
\begin{aligned}
& \left\langle u^{2}(z, t)\right\rangle \approx\left(\frac{g}{N}\right)^{2}\left\langle\left(\frac{\rho_{a}^{\prime}}{\bar{\rho}_{a}}\right)^{2}\right\rangle \\
& F_{u}\left(k_{z}\right) \approx\left(\frac{g}{N}\right)^{2} F_{a}\left(k_{z}\right)
\end{aligned}
$$

where $N$ is buoyancy frequency, here we take $N$ value of $2 \pi$ / (300 s).

The vertical wave number spectra for 1, 2 and 3 March 1996, averaged over the respective observation periods and for the altitude range from $84 \mathrm{~km}$ to $99 \mathrm{~km}$, are plotted in Fig. 4. The photon noise floors have been subtracted and the power law fits over the wave number range $m=2 \pi /(10 \mathrm{~km})$ to $2 \pi /(1 \mathrm{~km})$ are also plotted on each spectra. For reference the saturated power spectral density $F_{s}(m)=N^{2} /\left(6 \mathrm{~m}^{3}\right)$ predicted by linear instability theory also plotted in Fig. 4.

\section{Discussion}

The slopes of the vertical wave number spectra in the mesopause varied from -2.17 to -2.65 , the mean slope is 2.38. The magnitudes in this paper at $m=2 \pi /(4 \mathrm{~km})$ varied from $3.74 \times 10^{5}\left(\mathrm{~m}^{2} / \mathrm{s}^{2}\right) /(\mathrm{cyc} / \mathrm{m})$ to $2.05 \times 10^{6}\left(\mathrm{~m}^{2} / \mathrm{s}^{2}\right) /(\mathrm{cyc} /$ $\mathrm{m})$. Senft and Gardner (1991) reported their observations that the $m$-spectra shapes were highly variable at Urbana. The slopes varied from -2.20 to -3.55 with an annual mean of -2.90 and the spectral magnitude at $m=2 \pi /(4 \mathrm{~km})$ varied by more than a factor of 10 throughout the year with maximum values in summer and an annual mean of $4.4 \times 10^{5}$ $\left(\mathrm{m}^{2} / \mathrm{s}^{2}\right) /(\mathrm{cyc} / \mathrm{m})$. Beatty et al. (1992) reported a mean of 2.98 and $2.9 \times 10^{5}\left(\mathrm{~m}^{2} / \mathrm{s}^{2}\right) /(\mathrm{cyc} / \mathrm{m})$, respectively, for the mean slope and magnitude for all of the Arecibo data.

Because the lidar observation period each day was only lasted about 2.4 hours, so the contents of long period wave ( $T>2.4$ hours) could not be received by our lidar. In addition the atmospheric density spectra averaged for the altitude range only from 84 to $99 \mathrm{~km}$, the contents of long vertical 
Table 1. Comparison of the magnitudes of the spectra.

\begin{tabular}{lcccc}
\hline & $\begin{array}{l}F_{u}(2 \pi /(5 \mathrm{~km})) \\
(\mathrm{m} / \mathrm{s})^{2} /(\mathrm{cyc} / \mathrm{m})\end{array}$ & $\begin{array}{l}F_{u}(2 \pi /(4 \mathrm{~km})) \\
(\mathrm{m} / \mathrm{s})^{2} /(\mathrm{cyc} / \mathrm{m})\end{array}$ & $\begin{array}{l}F_{u}(2 \pi /(3 \mathrm{~km})) \\
(\mathrm{m} / \mathrm{s})^{2} /(\mathrm{cyc} / \mathrm{m})\end{array}$ & $\begin{array}{l}F_{u}(2 \pi /(1 \mathrm{~km})) \\
(\mathrm{m} / \mathrm{s})^{2} /(\mathrm{cyc} / \mathrm{m})\end{array}$ \\
\hline 1 March & $6.3 \times 10^{5}$ & $3.74 \times 10^{5}$ & $1.82 \times 10^{5}$ & $8.98 \times 10^{3}$ \\
2 March & $3.31 \times 10^{6}$ & $2.05 \times 10^{6}$ & $1.13 \times 10^{6}$ & $8.14 \times 10^{4}$ \\
3 March & $1.47 \times 10^{6}$ & $1.07 \times 10^{6}$ & $5.63 \times 10^{5}$ & $5.09 \times 10^{4}$ \\
Mean & $1.80 \times 10^{6}$ & $1.16 \times 10^{6}$ & $6.25 \times 10^{5}$ & $4.70 \times 10^{4}$ \\
$F_{s}(m)$ model & $8.84 \times 10^{6}$ & $4.75 \times 10^{6}$ & $2.08 \times 10^{6}$ & $7.50 \times 10^{4}$ \\
\hline
\end{tabular}

wavelength waves $\left(\lambda_{z}>15 \mathrm{~km}\right)$ were not included in the spectra. These two reason may explain why the slopes in this paper are a little shallower than the values measured at other sites.

The magnitudes of the spectra in this paper and the saturated power spectral model are summarized in Table 1. The lidar values are artificially depressed by a factor of 0.5 0.75 (Senft et al., 1993) because the data were filtered with a cutoff frequency of $2 \pi /(1 \mathrm{~h})$ and a cutoff wavelength $2 \pi /(1 \mathrm{~km})$ before the spectra were computed. The lidar $m$ spectra do not include gravity wave energy in the frequency range $2 \pi /(1 \mathrm{~h})$ to $N$. Thus, if we account tor filtering effects, the lidar spectra of 2 March are saturated at the range of $m$ $>2 \pi /(3 \mathrm{~km})$. From Table 1 we can see that the magnitude of 2 March is much big than 1 and 3 March, which may show an enhanced wave activity occurred during the observation.

\section{Conclusions}

The vertical wavenumber spectra shown in Fig. 4 are generally within a factor of 1 to 8 of the saturated spectrum for vertical scales from $10 \mathrm{~km}$ to $1 \mathrm{~km}$, suggesting general consistency with the saturated spectral model in spectral amplitude. Also apparent are variations in the wavenumber spectra from day to day. It reveals that the wave activities in the mesopause region at Wuhan are strong.

Unfortunately, the signal levels below $60 \mathrm{~km}$ altitude were not adequate to compute many of the gravity wave parameters from the upper stratosphere data. For more detailed studies of dynamics in the mesosphere and stratosphere, much more powerful lidars are required.
Acknowledgments. The authors wish to express their sincere appreciation to Dr. M. Ishii (C.R.L.) for his valuable help in writing this paper. The work was supported by the funds of the Chinese Academy of Science.

\section{References}

Ai, Y., S. Lu, X. J. Zhang, and S. S. Gong, Characteristics of the sodium layers observed by the laser radar at Wuhan, China J. Chinese Laser, No. 5, 56-59, 1998.

Beatty, T. J., C. A. Hostetler, and C. S. Gardner, Lidar observation of gravity waves and their spectra near the mesopause and stratopause at Arecibo, J. Atmos. Sci., 49, 477-496, 1992.

Gardner, C. S. and D. G. Voelz, Lidar studies of the nighttime sodium layer over Urbana, Illinois 2. Gravity wave, J. Geophys. Res., 92, 46734694, 1987.

Gong, S. S., X. Z. Zhen, X. J. Xue et al., The first observation of sodium layers by laser radar at Wuhan in China, Science in China (Series A), 27(4), 369-373, 1997.

Liu, C. H., World Ionosphere/Thermosphere Study Handbook, pp. 155162, Volume 2, Chapter 6, University of Illinois, 1989.

Manson, A. H., C. E. Meek, and Q. M. Zhan, Gravity wave spectra and direction statistics for the mesophere as observed by MF radars in the Canadian Prairies $\left(49^{\circ} \mathrm{N}-52^{\circ} \mathrm{N}\right)$ and at Tromso $\left(69^{\circ} \mathrm{N}\right)$, J. Atmos. Terr. Phys., 59, 993-997, 1997.

Senft, D. C. and C. S. Gradner, Seasonal variability of gravity wave activity and spectra in the mesopause region at Urbana, J. Geophys. Res., 96, 17,229-17,264, 1991.

Senft, D. C., C. A. Hostetler, and C. S. Gradner, Characteristics of gravity wave activity and spectra in the upper stratosphere and upper mesosphere at Arecibo during early April 1989, J. Atmos. Terr. Phys., 55, 425-439, 1993.

Y. Ai (e-mail: aiyong@public.wh.hb.cn), X. J. Zhang, S. Lu, and S. S. Gong 